\title{
Liquidación de sentencia
}

\author{
Judgment settlement
}

Alejandro Abal Oliü ${ }^{1}$

${ }^{1}$ Universidad de la República.

Orcid ID: https://orcid.org/0000-0002-7407-4008

https://doi.org/10.22235/rd.v18i2.1700

ReSUMEN: En este artículo se trasmiten las conclusiones de la investigación cumplida en torno al campo normativo, a las principales reflexiones académicas y a la jurisprudencia más relevante, sobre el procedimiento que el Código General del Proceso de Uruguay regula bajo el nombre de "Liquidación de sentencia".

Palabras clave: liquidación de sentencia, condena a suma ilíquida, ejecución de sentencia.

ABSTRACT: In this article, the conclusions of the completed research on the normative field, the main acad emic reflections and the most relevant jurisprudence are transmitted on the procedure that the General Code of the Uruguay Process (C.G.P.) regulates under the name of "Settlement of judgment".

KEYWORDS: judgment settlement, sentence to illiquid sum, sentence execution

Sumario: 1. Noción de liquidación de sentencia. 2. La liquidación de sentencia Żforma parte de la etapa de conocimiento o de la etapa de ejecución? 3. La liquidación de sentencia, ¿̇es un incidente? 2 ¿̇la sentencia que le pone fin es interlocutoria o definitiva? 4. ¿Cuándo corresponde seguir el procedimiento de liquidación de sentencia? 4.1. ¿Cuándo existe "iliquidez"? 4.2. ¿Cuándo es admisible que se remita la liquidación a este procedimiento del art. 378 del C.G.P.? -¿̇Puede el actor pedir en su demanda dicha remisión? - Si el actor solicitó una condena al pago de cantidad líquida, ¿̇puede el juez condenar al pago de cantidad ilíquida y disponer la remisión al procedimiento en estudio para luego liquidarla? - Si lo solicitado por el actor y resuelto en la sentencia no es estrictamente una condena al pago de frutos, mejoras, daños o perjuicios, sino al pago 
de horas extras, o al pago del precio de costumbre por arrendamientos de obra, o al pago de honorarios profesionales, etc., ¿̇es posible acudir al procedimiento previsto en el art. 378 del C.G.P.? - ¿YY si el adeudo ilíquido no resulta de una sentencia sino de otros actos jurídicos asimilados a las sentencias, pero diferentes de estas? 5. Competencia. 6. ¿Quién puede iniciar el procedimiento de liquidación de sentencia? 7. ¿̇ué se puede reclamar en la demanda de liquidación se sentencia? 8. Trámite para liquidar una cantidad debida por frutos o mejoras. 9. Trámite para liquidar una cantidad debida por daños y periuicios. 10. Sentencia de liquidación. 11. Recursos. 12. Conclusiones. Bibliografía. 


\title{
NOCIÓN DE LIQUIDACIÓN DE SENTENCIA
}

\author{
Decía Couture ${ }^{2}$ explicando la liquidación de sentencia, que
}

Frecuentemente la sentencia (de condena) no contiene una condena específica en sumas de dinero líquidas y exigibles. La coacción en este caso es imposible y antes de pasar a ella es menester realizar un proceso previo de liquidación. Se dice, entonces, que el proceso se divide en dos etapas. La primera de ellas, destinada a determinar el 'an debeatur'; la segunda, destinada a determinar el 'quantum debeatur'.

Precisamente por esta razón es que en el Proyecto de Código de este autor y a diferencia de lo que sucedía en el derogado C.P.C. y sucede actualmente en el C.G.P., no se incluía a este trámite de liquidación de sentencia dentro del proceso o etapa de ejecución (bien que, para ser precisos, tampoco ese Proyecto de Código de Couture lo incluía propiamente en el proceso o etapa de conocimiento, sino por separado, en una "Parte Tercera" que comprendía las alternativas comunes a todos los procesos).

Quizás para comprender bien de lo que trata la llamada liquidación de sentencia, deberíamos preguntarnos que tendría que suceder cuando en una sentencia y pese a estar el juez convencido de que el demandado debe ser condenado, por carencias probatorias no se puede establecer cual es la concreta cantidad líquida que el mismo debe abonar al actor.

Pues en principio y conforme a la regla general de la necesaria congruencia de las sentencias, al no poder establecerse, por carencias probatorias al respecto, cual es la cantidad líquida a cuyo pago la sentencia debe condenar al demandado, no podría hacer lugar a la pretensión del actor y debería rechazarse la misma.

Por ende, además de que el actor debería plantear en su demanda cuál es la concreta cantidad líquida que pretende, debería proponer en ese proceso todos los medios de prueba

Eduardo J. Couture, Fundamentos de Derecho Procesal Civil, 3era. ed. (Buenos Aires, Depalma, 1966), 457. 
necesarios no sólo para demostrar la responsabilidad del demandado, sino también para acreditar la suma líquida que el mismo le adeuda.

Sin embargo, el C.G.P. permite que una sentencia solamente condene al demandado a pagar cantidades de dinero por dańos y perjuicios, frutos o mejoras, sin indicar exactamente cuál es su monto, para luego, a través de la llamada "liquidación de sentencia” establecer, a través de otra sentencia que complementa a la anterior y luego de un procedimiento destinado a determinado, cual será el monto líquido de dicha obligación.

¿Por qué, como resulta del Derecho Comparado, en casi todo ordenamiento procesal se suele establecer una regulación procesal semejante?

En última instancia por una razón de economía procesal.

Se trata, en efecto, de que cuando se inicia un proceso en el que se reclama una condena del demandado que en definitiva determinaría su obligación de pagar sumas de dinero por daños y perjuicios, frutos o mejoras, las partes deberían hacer un esfuerzo probatorio muy importante no solo para determinar si existió o no responsabilidad del demandado, sino también para determinar el monto de esas cantidades de dinero que en caso de existir responsabilidad el mismo debería abonar al actor.

Para evitar que en caso de que no se condene al demandado las partes hayan tenido que hacer ese despliegue probatorio destinado no solo a determinar si corresponde o no la condena, sino también al monto preciso ("líquido") que debería tener la misma, y evitar que en definitiva ello resulte inútil en el caso de que el proceso no concluya con esa condena, las regulaciones procesales (entre ellas la de Uruguay), permiten que en una primera etapa se resuelva acerca de si corresponde o no la condena y luego, para el caso de que la sentencia determine la condena, en una segunda etapa se resuelva sobre el monto líquido de la misma.

Esta última etapa es, justamente, la que se denomina "liquidación de sentencia" y, obviamente, ella no existirá, será innecesaria, si ya en la normal etapa de conocimiento se logró determinar la cantidad líquida (es decir la "suma”) que comprende la condena del demandado.

De manera que primero se determina si existe o no una obligación del demandado, y luego, en caso de que una sentencia ejecutoriada establezca que existe dicha obligación, se determina el monto de la misma (aunque bueno es recordar que incluso ese monto puede luego sufrir alguna variación durante la posterior etapa de ejecución, puesto que a esa cantidad ahora "líquida" deberán añadirse otras cantidades "fácilmente liquidables" por conceptos como los de reajustes e intereses y algún otro rubro). 
Se trata entonces y como se suele decir, de que eventualmente pueden presentarse en un proceso de ejecución (de "ejecución” en el sentido en que emplea la expresión Barrios de Ángelis), dos etapas de la formación progresiva de una única sentencia de condena, que es la que en definitiva se va luego a ejecutar (una única sentencia de condena comprensiva ella de dos sentencias parciales que se complementan, en tanto una determina el "an debeatur", y la otra, si la primera fue de condena, el "quantum debeatur").

\section{LA LIQUIDACIÓN DE SENTENCIA ¿FORMA PARTE DE LA ETAPA DE CONOCIMIENTO O DE LA ETAPA DE EJECUCIÓN?}

Se ha discutido bastante acerca de la naturaleza de la actividad que se cumple durante la liquidación se sentencia. ¿ Se trata de una actividad propia de la etapa de conocimiento, o de una actividad propia de la etapa de ejecución?

En opinión generalmente compartida, se entiende que se trata de una actividad propia de la etapa de conocimiento, puesto que con la sentencia que la concluye nunca se "ejecuta" propiamente ninguna sentencia, sino que solamente se complementa la original sentencia que estableció la condena del demandado pero sin determinar la cantidad líquida comprendida en dicha condena, obteniéndose recién a partir de ese momento un "título de ejecución" habilitante del inicio de la etapa de ejecución del proceso según prevé el art. 377 del C.G.P.

Como señala en igual sentido Klett ${ }^{3}$ "El proceso de liquidación constituye un auténtico proceso de conocimiento, en virtud del cual se crea el título de ejecución, inexistente hasta ese entonces por carecer de la suma líquida que constituye la condena”.

Este procedimiento no forma entonces parte de la etapa de ejecución sino de la etapa de conocimiento del proceso.

Sin embargo, lo que llama a confusión es el lugar donde ha colocado el legislador su regulación dentro del C.G.P., dado que la disposición que refiere directamente a esta liquidación de sentencia (art. 378) se encuentra inserta en el Capítulo II ("Vía de apremio") del Título V ("Procesos de ejecución”) del Libro II (“Desarrollo de los procesos").

Selva Klett, Proceso Ordinario, t. III, (Montevideo, F.C.U., 2014) 233. 
Empero, esta asistemática localización del art. 378 del código no puede llevarnos a concluir que la naturaleza de esta actividad es la propia de la etapa de ejecución, puesto que claramente ella corresponde a la etapa de conocimiento del proceso.

En cualquier caso, si bien antes del C.G.P. y de la ley no 19.090 los problemas cuya solución dependía de esta respuesta eran muchos más que actualmente, el concluir de esta forma (que la liquidación de sentencia forma parte de la etapa de conocimiento) aún permitiría plantear -como por ejemplo lo hace Klett- que, por ejemplo, son aplicables a este procedimiento las reglas propias de la etapa de conocimiento, como las que establecen cierta iniciativa probatoria del tribunal, o la posibilidad de alegar hechos nuevos o de presentar pruebas nuevas luego de la demanda de liquidación y evacuación del traslado por el demandado, etc.

\section{LA LIQUIDACIÓN DE SENTENCIA, ¿ES UN INCIDENTE? ¿LA SENTENCIA QUE LE PONE FIN ES INTERLOCUTORIA O DEFINITIVA?}

Ahora bien, para esta segunda parte de la etapa de conocimiento de un proceso que comenzó con la demanda y que terminó con una sentencia definitiva parcial (una sentencia solamente parcial porqué no fijó el monto de la condena, sino que se limitó a condenar), el C.G.P. ha establecido en su art. 378 que el trámite a seguir es el mismo de los incidentes ("vía incidental" expresa la disposición).

Sin perjuicio de profundizar luego al respecto, adelanto que considerar que este procedimiento es verdaderamente un incidente llevaría a concluir que se deben aplicar a la sentencia que lo termina todas las reglas propias de una sentencia interlocutoria, lo cual conduce a un absurdo.

Un absurdo pues si el monto líquido se fija ya en la sentencia definitiva que normalmente concluye la etapa de conocimiento (es decir que se fija sin necesidad de seguir este procedimiento de liquidación de sentencia), a esa liquidación del adeudo contenida en aquella sentencia definitiva se le aplicarían necesariamente las reglas propias de las sentencias definitivas (en cuanto a plazos de estudio, integrantes de tribunales colegiados que deben intervenir en ese estudio y en la votación, votos conformes que se requieren para la aproba- 
ción, e inclusive la posibilidad de que la sentencia sea susceptible de impugnación por los recursos de casación y de revisión); y, en cambio, si para fijar ese mismo monto líquido se debió tramitar la liquidación de sentencia y ella fuera un verdadero incidente, la sentencia que lo fija sería una sentencia interlocutoria, y ello conduciría a aplicar a la misma las reglas de esas sentencias interlocutorias (en cuanto a plazos de estudio, integrantes de tribunales colegiados que deben intervenir en ese estudio y en la votación, votos conformes que se requieren en esos casos para la aprobación, e inclusive la posibilidad de que la sentencia sea o no susceptible de impugnación por los recursos de reposición, casación y revisión).

Estando vigente el derogado C.P.C. la discusión al respecto se centraba no tanto en si realmente lo que se regulaba en los arts. 496 a 506 de ese código era propiamente un incidente, sino precisamente en cual era la calidad de la sentencia que concluía esa tramitación.

Algunos autores (por ejemplo, Rafael Gallinal, Enrique Tarigo, José Arlas, Dante Barrios de Ángelis, Jorge Marabotto) entendían que se trataba de una sentencia interlocutoria y que como tal debía ser considerada, en tanto que otros autores (Raúl Moretti, Luis A. Viera, Jaime Teitelbaum) consideraban que se trataba de una sentencia definitiva.

Sancionado el C.G.P. encontramos explicitado en su art. 378.1 que el trámite que se debe seguir para la liquidación de sentencia es el de la "vía incidental".

Ello plantea varios problemas, relacionados también la mayoría de los mismos con la sentencia y algunos de los cuales fueron expresamente solucionados por la redacción dada al artículo 378 por la ley no 19.090 .

Sin embargo la naturaleza de la sentencia (interlocutoria simple, interlocutoria con fuerza de definitiva, definitiva) no ha quedado zanjada por la citada ley no 19.090 , por lo que dependiendo de la conclusión a la que se arribe sobre ello resultarán de aplicación unas u otras reglas sobre plazos de estudio, integrantes de tribunales colegiados que deben intervenir en ese estudio y en la votación de la sentencia en segunda instancia o aún en casación, votos conformes que se requieren para su aprobación, e inclusive la posibilidad de que la sentencia sea susceptible de impugnación por los recursos de reposición, casación y revisión.

Como se verá más adelante, en mi opinión la sentencia que pone fin al trámite de la liquidación de sentencia -pese a tratarse de un procedimiento que sin ser un incidente sigue por disposición legal el tracto de los incidentes tramitados fuera de audiencia- es una sentencia definitiva. 


\section{¿CUÁNDO CORRESPONDE SEGUIR EL PROCEDIMIENTO DE LIQUIDACIÓN DE SENTENCIA?}

La pregunta ahora formulada conduce a considerar por lo menos dos cuestiones diferentes: a) cuándo es que existe "iliquidez" de la condena, habilitante así de este procedimiento de liquidación de sentencia, y b) cuándo es admisible que el juez remita la liquidación de la condena a este procedimiento de liquidación de sentencia.

\section{1. ¿CUÁNDO EXISTE "ILIQUIDEZ"?}

Como ya expliqué anteriormente ${ }^{4}$,

Estrictamente puede sostenerse que es líquida aquella obligación cuantitativamente determinada en términos de una unidad de medida (es este caso una unidad de dinero, como el peso, el dólar, el rublo, el franco, etc.) y que si la determinación requiere alguna operación adicional -fácil o no- la obligación ya no es líquida; como ocurre por ejemplo si tenemos una obligación documentada de pagar \$ 10.000 más los intereses, pero no se establece el monto de los últimos, sino que éste debe determinarse en base a la tasa de interés que en el mismo documento se establece y por el período de tiempo que también en dicho documento se señala. Tal parece ser lo que sostuvo Laurent.

De todas formas, luego de la ley no 19.090 en el primer inciso del art. 377 del C.G.P. que establece cuales son los "títulos de ejecución", ahora se prevé explícitamente que no es necesario que para ser tales contengan la obligación de pagar una cantidad de dinero exactamente "liquida", sino que puede tratarse de una cantidad de dinero "fácilmente liquidable"; de donde entiendo que merced a lo que resulta del contexto (e inclusive quizás con el apoyo del art. 1502 del Código Civil como desde antes sostenía Jorge Gamarra), debe interpretarse que las "cantidades ilíquidas" a las que refiere el art. 378 no comprenden a aquellas cantidades que pueden liquidarse fácilmente (por ejemplo, a través de simples operaciones matemáticas como la correspondiente a un cálculo de intereses sobre la base de una tasa fija), de donde si la cantidad es fácilmente liquidable no debe seguirse este procedimiento del art. 378 sino que en todo caso deberá procederse como indica el art. 359 del mismo código. 191.

Alejandro Abal Oliú, Estudios del Código General del Proceso, tomo III, 2da. ed. (Montevideo, F.C.U., 2000), 
Por otro lado y como ya proponía por ejemplo Jaime Teitelbaum ${ }^{5}$ - aclarando que concluía así "aunque el CGP no repite la disposición del art. 506 CPC”- sigue siendo posible ejecutar parcialmente una sentencia de condena cuando la misma establece la liquidez de solamente una parte de la obligación, de donde conforme resulta del art. 378.1 del código este procedimiento de liquidación de sentencia referirá en tal caso solamente a una parte de la sentencia (obviamente la parte de la misma en la que se condena a abonar una cantidad ilíquida).

\section{2. ¿CUÁNDO ES ADMISIBLE QUE SE REMITA LA LIQUIDACIÓN A ESTE PROCEDIMIENTO DEL ART. 378 DEL C.G.P.?}

\section{¿Puede el actor pedir en su demanda dicha remisión?}

Lo cierto es que, nuevamente por falta de sistematización, el C.G.P. no establece directamente en ningún lugar que el actor pueda pedir en su demanda una condena al pago de una cantidad ilíquida.

Sin embargo, advierto que al menos por lo que resulta del numeral 6 del art. 117, si bien normalmente "el valor de la causa (...) deberá ser determinado precisamente", cuando "ello no fuera posible" el actor podría pedir en su demanda la condena a una cantidad ilíquida, aunque en ese caso "deberá justificarse la imposibilidad y señalarse su valor estimativo, indicándose las bases en que se funda la estimación”.

De manera que si bien el pedido del actor en tal sentido estará condicionado a que le resulta imposible indicar la cantidad líquida (o fácilmente liquidable, como ya expliqué) que reclama -lo que además deberá “justificar”- entiendo que si lo hace deberá al menos y necesariamente indicar cual es la cantidad que estima que debe establecer la condena y cuales son las "bases" para luego liquidarla.

Aunque ello no es lo que ha sostenido Uriarte ${ }^{6}$, quién se basa en que la "amplitud del texto actual nos lleva a sostener que la sentencia de condena ilíquida puede o no contener las bases de la liquidación. Por otra parte, la lectura del artículo 11 del C.G.P. nos reafirma en esta convicción”, personalmente coincido con lo que ya en 1995 postulaba Tarigo ${ }^{7}$,

\footnotetext{
Jaime Teitelbaum, "Proceso de ejecución y vía de apremio" en Rev. Uruguaya de Der. Procesal, (4/1995), 516.

Gonzalo Uriarte, "Algunas reflexiones sobre el proceso de liquidación de sentencia", en Tribuna del Abogado (2003), no 134, 6; y "Vía de apremio. Algunos títulos y preparación de la misma”, en Estudios sobre el proceso de ejecución en homenaje a Enrique E. Tarigo de Autores Varios (Montevideo, F.C.U., 2006), 110.

Enrique Tarigo, "Frente a la sentencia definitiva que condenó a indemnizar daños y perjuicios y fijó las bases de tal liquidación, la sentencia interlocutoria de liquidación de sentencia no puede dejar de fijarlos”, en Rev. Uruguaya de 
cuando sostenía que la redacción del C.G.P. -incluido lo que dispone el numeral 6 del art. 117- "supone la negación de la tercera posibilidad prevista por el art. 478 C.P.C., esto es, la posibilidad de la condena genérica”.

De manera que el actor puede pedir la condena del demandado al pago de una suma ilíquida, sin perjuicio de lo cual deberá estimar cuál es la cantidad adeudada y justificar porqué no ha podido liquidarla y, además, indicar las “bases” para la liquidación posterior.

Añado a lo anterior que esta solicitud de condena al pago de una cantidad ilíquida no es admisible cuando el proceso refiere a la materia laboral, en tanto el art. 8 de la ley no 18.572 establece que en tal caso la demanda "Deberá incluir el valor total de la pretensión y la liquidación detallada de cada uno de los rubros reclamados”. Sin perjuicio de ello y de lo que se verá a continuación acerca de si es admisible que una sentencia se remita a este procedimiento cuando el actor solicitó -como en estos procesos de materia laboral- la condena a una cantidad líquida, a veces los jueces de trabajo igual siguen difiriendo para un posterior procedimiento de liquidación de sentencia el establecer la cantidad líquida de la condena, y ello pese a que el art. 5 de la ley no 18.847 modificó el art. 15 de la ley no 18.572 estableciendo -como se advertirá expresamente- que "las sentencias que condena al pago de créditos laborales de cualquier naturaleza deberán establecer el monto líquido de los mismos, incluidas las multas, intereses, actualizaciones y recargos que correspondieren”.

\section{Si el actor solicitó una condena al pago de cantidad líquida, ¿puede el juez con-} denar al pago de cantidad ilíquida y disponer la remisión al procedimiento en estudio para luego liquidarla?

De acuerdo a lo que establecía la letra del art. 478 del derogado C.P.C. parecía admisible (aunque la disposición no era de fácil interpretación en ese sentido) que aunque el actor hubiera solicitado una condena del demandado al pago de una cantidad líquida (o fácilmente liquidable), cuando el juez no pudiera fijar la cantidad adeudada podía remitirse a la liquidación de sentencia (sin perjuicio de que cuando la sentencia ni siquiera indicaba las bases de la liquidación, se discutía en Doctrina y Jurisprudencia acerca de cuál era el procedimiento a seguir para esa liquidación: si el de liquidación de sentencia, o el del proceso ordinario o algún otro).

Sin embargo, ninguna disposición del actual código, es decir del C.G.P. indica -ni siquiera indirectamente- que el juez está autorizado a no seguir la regla general o principio de la necesaria congruencia de las sentencias, y a dejar de pronunciarse -acogiéndola o no- respecto

Der. Procesal, (2/1995), 228. 
a la parte de la pretensión del actor referida a la suma (liquida o fácilmente liquidable) a cuyo pago solicita que se condene al demandado.

La verdad es que lo que establece el art. 378.1 del C.G.P. es que la sentencia puede condenar al pago de cantidad ilíquida, pero eso en realidad supone, como recién vimos que lo puede hacer, que el actor solicito una condena a cantidad líquida.

Lo que sí entiendo es que en estos casos -si entiende que debe condenar pero no encuentra fuentes de prueba que se hayan aportado y que tengan eficacia para determinar si es correcta la cantidad reclamada por el actor- lo que el Juez podría hacer es acudir al procedimiento previsto en el art. 1611 del Código Civil (deferir el juramento estimatorio al actor); procedimiento que ha sido extensamente analizado en la Novena Sección del Capítulo Cuarto de la Sexta Parte de Derecho Procesal (tomo IV, F.C.U., Montevideo, 3era. ed., 2018), a lo que me remito.

Claro que conforme a la citada disposición ello está limitado a los supuestos de procesos sobre obligaciones "civiles" (en el sentido de no "naturales": art. 1441 del Código Civil), nacidas de "delito, cuasidelito o dolo" (lo que excluiría a las obligaciones nacidas de contratos o cuasicontratos), en los que se reclama una suma concreta y el juez duda "sobre el número o valor real y de afección de las cosas o sobre el importe de los daños o perjuicios". Bien que todo ello sin perjuicio de que también se puede acudir al juramento estimatorio en los supuestos de los arts. 664 y 684 del Código Civil, 684 y 742 del Código de Comercio, e incluso hasta en el supuesto previsto en el art. 107.4 del propio C.G.P.

Y añado aún que, en ciertos casos, cuando se solicita en la demanda la condena al pago de una cantidad líquida y el juez considera que el adeudo existe pero que no hay fuentes de prueba que le permitan determinar su entidad, antes de dictar sentencia también podría disponerse de oficio la producción de otros medios de prueba, en particular a través de las llamadas "diligencias para mejor proveer" (previstas en el art. 193 del C.G.P.).

Finalmente, no puedo dejar de mencionar las conclusiones de la Doctrina respecto, en particular, a la dificultad de determinar con precisión el monto de un lucro cesante futuro. En estos casos enseña por ejemplo Jorge Gamarra ${ }^{8}$ que:

La gravitación de los factores de incertidumbre, y los obstáculos existentes para cuantificar el ingreso en los casos que acaban de mencionarse, condujeron a elaborar dos reglas generales. En primer lugar, las dudas y dificultades (que son aquí innegables y de gran entidad) nunca deben impedir el resarcimiento. (...) En segundo lugar, y como consecuencia necesaria de lo dicho, debe admitirse que las liquidaciones realizadas en esta área del perjuicio serán 'inevitablemente inexactas' o 'aproximadas', ya que 'no es posible llegar a resultados de absoluta precisión'. La máxima que se

8 Jorge Gamarra, Tratado de Derecho Civil Uruguayo, t. XXIV (Montevideo, F.C.U., 1992), 101 y 102/103. 
deduce de esta constatación es la validez y admisibilidad de una 'liquidación imperfecta’ y la derogación parcial (en la materia) del principio general que exige la prueba del monto preciso del dańo. Por consiguiente, que el perjuicio no se encuentre exactamente cuantificado en su entidad monetaria no es impedimento para que el juez lo liquide en forma aproximada. Ahora bien, la terminología 'estimación inexacta o imperfecta' no equivale a operación errónea o equivocada; simplemente reconoce la imperfección insita en la naturaleza de las cosas. El juez debe hacer todo lo que está a su alcance para que la operación de cálculo valore en la medida posible los datos que suministra la realidad y motivas adecuadamente su pronunciamiento, demostrando así que la sentencia no es antojadiza o arbitraria, sino la que razonablemente conviene al caso concreto.

Asimismo, Gamarra ${ }^{9}$ también explica que en aquellos casos en los que está claramente probado el daño concreto y ya existente, pero "cuyo monto preciso es imposible o muy difícil de acreditar" (particularmente en supuestos de daño a la persona), el juez debería acudir a la que empleando la terminología usual en Italia denomina "liquidación equitativa", y a cuya explicación por el propio autor ahora me remito.

Señalo, de todas formas, que lo que de momento estoy analizado es la admisibilidad de acudir para determinar la entidad de la condena -dentro de la normal etapa de conocimiento del proceso- al juramento estimatorio, a la producción de medios de prueba dispuesta de oficio o a estas liquidaciones imperfecta o equitativa. Ya veremos más adelante si estos mecanismos también pueden admitirse en los casos en los que habiéndose solicitado la condena al pago de una suma ilíquida (bien que indicando las bases de la liquidación), también pueden emplearse los mismos en la etapa de liquidación de sentencia.

Mas, concluyendo sobre lo analizado, si el actor solicitó una condena al pago de cantidad líquida, el juez no puede condenar al pago de cantidad ilíquida y disponer la remisión al procedimiento en estudio para luego liquidarla, sino que debe encontrar la solución a través de alguno de los citados mecanismos procesales.

Empero, no puedo dejar de seńalar que aunque el código en ningún lugar lo autorice a menudo los jueces se apartan de la regla de la congruencia, y pese a que se les ha solicitado por el actor la condena al pago de una suma líquida (o fácilmente liquidable), dejan de pronunciarse sobre la cantidad de dinero correspondiente a la obligación a cuyo pago se condena al demandado, y se remiten para fijar el monto de la condena al procedimiento de liquidación de sentencia previsto en el art. 378, lo cual considero reprochable.

Agrego ahora a esto último que, sin embargo, ha habido tribunales y autores que aún sin plantearse este problema ni las soluciones expuestas, al menos se han preocupado de sostener que cuando se pide la condena al pago de una cantidad líquida y existen elementos o medios Gamarra, Tratado, t. XXIV, 255. 
suficientes (particularmente probatorios) para liquidarla, el juez no debe nunca remitir la liquidación a este procedimiento del art. 378 del C.G.P.

\section{Si lo solicitado por el actor y luego resuelto en la sentencia no es estrictamente} una condena al pago de frutos, mejoras, daños o perjuicios, sino al pago de horas extras, o al pago del precio de costumbre por arrendamientos de obra, o al pago de honorarios profesionales, etc., ¿es posible acudir al procedimiento previsto en el art. 378 del C.G.P.?

Tampoco existe ninguna disposición en nuestro Derecho Positivo que explícitamente indique que puede acudirse a este procedimiento cuando se trata de "liquidar" la cantidad de dinero que corresponde a una condena, y no nos encontramos ante una condena al pago de lo adeudado por frutos, mejoras, daños o perjuicios (sino, por ejemplo, ante una condena al pago del precio de costumbre por arrendamientos de obra, o al pago de horas cumplidas en un arrendamiento de servicios, si es que se entendiera que esta clase de contrato no está ya totalmente absorbida por el contrato de trabajo, etc.).

Empero podría quizás - por cierto que con mucho esfuerzo- intentarse encontrar la norma habilitante para emplear este procedimiento en otros supuestos, en lo que establece el ya citado numeral 6 del art. 117 del C.G.P., puesto que el mismo expresa que cuando no le es posible hacerlo al momento de la demanda el actor puede no indicar la suma exacta que reclama, sino solamente estimarla (indicando las bases en que se funda para la estimación), y nada expresa respecto a que ello solamente se pueda hacer cuando se reclaman frutos, mejoras, daños o perjuicios, lo que habilitaría a hacerlo en otros casos diferentes (como los señalados de condena al pago del precio de costumbre por arrendamientos de obra, etc.).

Por otro lado -y además de la posibilidad de argumentar que la norma habilitante se genera por integración a través de la analogía- también podría quizás intentar fundarse esa solución en el art. 378.1, dado que dicha disposición solamente exige para seguir este procedimiento de liquidación de sentencia que exista una sentencia que "condene al pago de cantidad ilíquida en todo o en parte".

En todo caso el problema que a continuación se plantearía sería el de cuál tendría que ser el procedimiento a seguir; es decir si el previsto en el art. 378.2 o el que indica el art. 378.3, a lo que entiendo que debería responderse que es este último, puesto que no se trata en definitiva de otra cosa que del mismo procedimiento que menciona el art. 378.1 (la normal "vía incidental”). 
Un supuesto particular que considerar es el referido a la posibilidad de que el actor reclame por este procedimiento no solamente la liquidación de las cantidades debidas por frutos, mejoras, daños o perjuicios, sino también la liquidación de los honorarios profesionales del abogado del actor a cuyo pago también se condenó al demandado.

$\mathrm{Al}$ respecto sostuvo Tarigo en determinado momento (año 2002) que ello era admisible, en mérito a que el procedimiento fijado por el art. 378.2 era el propio de los incidentes, y a que entonces era el mismo que establece para la "regulación de honorarios profesionales" el art. 144 de la ley no 15.750 , de donde sería admisible la acumulación de pretensiones que incluyera la liquidación de los honorarios adeudados.

Sin embargo y fuera de que cómo, se advertirá se trata de reclamar la liquidación de una cantidad de dinero que no se adeuda por frutos, ni por mejoras, daños o perjuicios, y que por lo tanto y como ya señalé es al menos dudoso que pueda emplearse al efecto el procedimiento previsto en el art. 378 del C.G.P., lo cierto es que el procedimiento previsto en el art. 144 de la ley no 15.750 no es exactamente el mismo del art. 378.2, en tanto en el primero intervendrá el abogado del favorecido por la condena en costos y en el segundo no, y en tanto en el primero no está previsto que si el demandado no controvierte la liquidación se deberá estar necesariamente a la presentada por el actor, y en cambio en el segundo ello no solo no está previsto sino que incluso se establece, además y expresamente, como es que debe regular el juez los honorarios con independencia de lo que haya expresado al respecto el actor.

\section{¿Y si el adeudo ilíquido no resulta de una sentencia sino de otros actos jurídicos asimilados a las sentencias, pero diferentes de estas?}

Señalaba también Teitelbaum ${ }^{10}$ que

Pese a referirse el art. 378 (solo) a "sentencia”, el procedimiento de liquidación es posible para otros títulos de ejecución, ya que el art. 378.2 finaliza "procederá igual solución cuando en otro acto jurídico se establezca deuda ilíquida exigible”. En consecuencia, es aplicable al laudo, transacción y convenios judiciales ilíquidos, aunque no en la ejecución de prenda e hipoteca que siempre contienen sumas líquidas.

Aun siendo posible seguir sosteniendo este postulado, aparece como acertada la observación de Valentin ${ }^{11}$ cuando anota que la sustitución que en el texto del art. 378.2 realizó la ley no 19.090 de "otro acto jurídico" por "otro título de ejecución” no es "feliz", puesto que

10 Teitelbaum, "Proceso de ejecución, 515.

11 Gabriel Valentin, La Reforma del Código General del Proceso (Montevideo, F.C.U., 2014), 369. 
según el art. 377 del C.G.P. no es posible que exista un "título de ejecución" si ya no establece que existe una deuda "líquida"; de donde por ejemplo y si tomamos literalmente este erróneo cambio que ha hecho la ley no 19.090 , un convenio celebrado durante la conciliación o una transacción o incluso un laudo que no establezcan ya una obligación líquida -y que por lo tanto no son "títulos de ejecución"- no podrían "liquidarse" por los procedimientos del art. 378 del código (y entonces quizás habría que seguir a ese efecto el trámite del proceso ordinario).

\section{COMPETENCIA}

Según el actual art. 372.1 del C.G.P. el juzgado que entendió en la primera instancia de la etapa de conocimiento entenderá también en la primera instancia de la etapa de ejecución y, por lo tanto, siendo que en el C.G.P. el procedimiento de liquidación de sentencia integra formalmente esta última etapa, para entender en la primera instancia de esta liquidación de sentencia está claro que será competente el mismo tribunal que lo fue en la primera instancia de la etapa de conocimiento.

Y aunque la citada disposición no lo menciona expresamente, también será el tribunal que entendió o debió entender en la segunda instancia de la etapa de conocimiento el que deberá entender en una eventual segunda instancia de la etapa de ejecución y, por ende, en una eventual segunda instancia del procedimiento de liquidación de sentencia.

\section{¿QUIÉN PUEDE INICIAR EL PROCEDIMIENTO DE LIQUIDACIÓN DE SENTENCIA?}

Parece claro que este procedimiento solamente puede iniciarse a solicitud de parte y nunca de oficio, bien que actualmente y merced a la nueva redacción que la ley $\mathrm{n}^{\circ} 19.090$ dio al art. 378.1 (siguiendo lo que ya postulaba Viera y vigente el C.G.P. retomó Cutrín Piñeiro y luego expresamente aceptó Uriarte), la demanda puede ser presentada por cualquiera de las dos partes. 
Ello plantea cierta complejidad cuando es el deudor (el demandado en lo principal) quién solicita liquidar la condena, en tanto los procedimientos previstos en los arts. 378.2 y 378.3 parten de la base de que quién presenta la demanda de liquidación es el actor (acreedor) y no el demandado (deudor), y el tracto procesal a seguir si presenta esta demanda el deudor no puede ser exactamente el previsto en estas disposiciones.

De allí que si es el deudor quién promueve la liquidación de una cantidad adeudada por frutos o mejoras, al hacerlo pareciera que deberá ya formular la liquidación, y que de ello se deberá dar traslado al acreedor y seguirse luego el procedimiento de los incidentes fuera de audiencia (art. 321 del código), sin perjuicio de que si el acreedor no contradice la liquidación presentada por el deudor se deberá estar a la presentada por este último (conforme al segundo inciso del art. 378.2 en redacción dada por la ley no 19.090).

Si la liquidación que promueve el deudor corresponde a una cantidad adeudada por daños o perjuicios, también deberá liquidar en su demanda dicha cantidad y tendrá que darse traslado de esa demanda al actor. Si este no controvierte la liquidación se estará a la presentada por el deudor. Si la controvierte entonces también en este caso se seguirá el trámite previsto en el C.G.P. para los incidentes fuera de audiencia.

\title{
¿QUÉ SE PUEDE RECLAMAR EN LA DEMANDA DE LIQUIDACIÓN DE SENTENCIA?
}

\author{
Como recuerda Nicastro ${ }^{12}$, resulta claro que
}

(...) lo único que se puede diferir a la vía de liquidación es la cuantificación o la determinación del monto de los dańos y perjuicios (o, en todo caso, de lo adeudado por frutos o mejoras). (...) Es decir, el diferimiento de la liquidación a la vía incidental solo procede cuando es posible arribar a la conclusión fundada sobre la existencia de los daños y de la obligación reparatoria (an debeatur) (...) A su vez, en la etapa liquidatoria no resulta procesalmente admisible pretender introducir cuestionamientos relativos al an debeatur no formulados oportunamente en la etapa anterior -puesto que ello vulneraría la cosa juzgada- ni que se insista en la defensa de argumentos desestimados con autoridad de cosa juzgada en la fase de conocimiento (...) Asimismo, se ha señalado que sería absolutamente contrario a la cosa juzgada admitir otras pautas u otros criterios que no se concretaron en la decisión que se debe liquidar. Además si el actor no pidió que se condenara

12 Gustavo Nicastro Seoane, "Cuestiones prácticas en el proceso de liquidación de sentencia previsto en el artículo 378 del C.G.P.”, en Rev. Judicatura (2016), nº 60, 136. 
a pagar determinado rubro (por ejemplo los intereses legales) en la etapa de conocimiento, no puede renovar su facultad de pedir en la etapa de liquidación (...) En cambio, aunque en la sentencia de condena a liquidar no se hubiese previsto el reajuste, conforme a lo dispuesto en el Decreto -Ley n ${ }^{\circ}$ 14.500, ello no impide que al liquidarse el rubro por la vía del art. 378 se incluya la actualización, puesto que dicho reajuste procede aun de oficio y la etapa liquidatoria es apropiada para imponer tal correctivo.

A su turno Klett ${ }^{13}$ nos presenta una sentencia del Tribunal de Apelaciones en lo Civil de 6to. turno en la que se indica que "(...) no corresponde -en la sentencia liquidatoria- realizar el cálculo aritmético de los reajustes e intereses, por la sencilla razón de que tanto los unos como los otros se devengarán hasta la fecha del pago y no hasta la fecha de la sentencia liquidatoria."

Por otro lado, y siempre acerca de lo que puede reclamarse en una demanda que inicia la liquidación de sentencia, Uriarte ${ }^{14}$ ha expresado que "El Tribunal de Apelaciones en lo Civil de $4^{\circ}$ turno ha tenido oportunidad de pronunciarse en forma afirmativa en dos oportunidades, señalando que 'debe admitirse la posibilidad de reclamación y reparación de los daños posteriores al fallo judicial pero no manifestados todavía, en naturaleza de daños futuros previsibles".

\section{TRÁMITE PARA LIQUIDAR UNA CANTIDAD DEBIDA POR FRUTOS O MEJORAS}

Cuando se trata de liquidar una cantidad debida por frutos o mejoras comienza el trámite, según el art. 378.2 del código, con una demanda de liquidación en la que se solicita intimar al condenado para que él presente esa liquidación (entiendo que esta demanda no necesariamente debe estar acompañada de la proposición de producir medios de prueba).

Para explicar la razón de que en este caso se trate de comenzar el procedimiento con una liquidación a presentar por el deudor y no por el actor, Viera ${ }^{15}$ expresa que

La razón por la cual la liquidación de los frutos se intima al deudor para que la presente y la de daños y perjuicios la formula directamente el ejecutante, estriba en que, respecto a los frutos, la ley entiende que el que se encuentra en mejores condiciones de saberlo es el ejecutado que los percibió, mientras que respecto a los daños y perjuicios es el ejecutante, que los sufrió, el que los conoce.

Klett, Proceso Ordinario, 238.

14 Uriarte, "Algunas reflexiones, 7.

15 Luis A. Viera, "Ejecución de sentencia", en Curso de Derecho Procesal del Instituto Uruguayo de Derecho Procesal, t. IV, 2da. ed. (Montevideo, F.C.U.,1987), 63. 
En la redacción original del art. 378.2 del C.G.P. el supuesto regulado refería solamente a la liquidación de una cantidad correspondiente a un adeudo por "frutos". La ley no 19.090 agregó a dicho supuesto la liquidación de una cantidad correspondiente a un adeudo por "mejoras".

Valentin ${ }^{16}$ explica esto señalando que "El legislador entiende que existe un rasgo fundamental que justifica esta incorporación: es que, en este supuesto, al igual que en el caso de los frutos, es el demandado quien realizó las mejoras y, por consiguiente, quien está en mejores condiciones de cuantificar su valor."

Ahora bien, otorgado el traslado al demandado (por seis días, art. 99 del C.G.P.) y presentada la liquidación por el mismo (en su caso proponiendo los medios de prueba que entienda que deben producirse), deberá darse traslado al actor (también por seis días), quién podrá formular una liquidación alternativa (u observaciones controvirtiendo la del demandado), proponiendo ahora también él los medios de prueba que entienda se deben producir, y luego se seguirá el trámite de los incidentes fuera de audiencia, lo que implica que se celebrará una audiencia (la que conforme al art. 321.2 se desarrollará de acuerdo con lo que disponen los numerales 1 y 4 del art. 346, "en lo pertinente").

Según el inciso segundo de este art. 378.2, si el demandado no presenta una liquidación habrá de estarse a la que presente el actor "salvo prueba en contrario" (prueba que se supone será la que resulte de fuentes de prueba ya obrantes en la primera fase del proceso o en el mismo procedimiento de liquidación, incluso las presentadas por el mismo actor acompañando su liquidación).

Asimismo, conforme ahora a la nueva redacción de este inciso segundo dada por la ley no 19.090, si al contestar la demanda el demandado presenta la liquidación y en el término del traslado que corresponde ella no es controvertida por el actor, deberá estarse a la liquidación que presentó el demandado (también en este caso "salvo prueba en contrario”).

Como se advertirá, en este caso se establece algo diferente a lo que resulta de la regla que sobre la admisión tácita de los hechos alegados se establece en el art. 135 del código, puesto que justamente según esa disposición unos de los hechos que no están comprendidos en la admisión tácita normal son aquellos que la parte demandada no tendría por qué conocer (como sería, en este caso para el actor incidental, la cuantificación de lo que se adeuda por frutos y que solo conoce el demandado incidental).

16 Valentin, La Reforma, 370. 
Aparte de ello, entiendo que esta admisión tácita -tanto de una como de la otra parte- no puede ser obstáculo para que el juez revise de oficio si la liquidación así admitida contradice las bases que para realizarla (y ya con calidad de cosa juzgada) estableció la sentencia que se está liquidando.

Mas, ¿qué sucede si el demandado, a quién se dio traslado de la demanda del actor, no presenta una liquidación de la cantidad que adeuda por frutos o mejoras?

Para considerar la respuesta debemos tener presente que lo previsto en el art. 378.2 es que al actor se le de traslado de la liquidación que presenta el demandado, pero no está previsto claramente como sigue el trámite si en el plazo del traslado (por seis días conforme a la regla general del art. 99) el demandado no presenta la liquidación (del texto del inciso segundo del art. 378.2 actualmente solo resultaría que el actor podría presentar una liquidación y que "se estará" a ella).

Sobre ello -en conclusión que comparto- expresaba Viera ${ }^{17}$ que "Aunque el código no lo diga hay que concluir, en esta segunda hipótesis que la vía incidental se suspende hasta que el actor presente su liquidación”.

A esto agregaba dicho autor -y aunque no resulta totalmente claro lo que dice al respecto quizás también Barrios de Ángelis- que de esta liquidación del actor debía darse traslado al demandado para que presente prueba si quiere, lo cual entiendo que no corresponde pues según interpreto -coincidiendo con Garderes- la "prueba en contrario" que menciona el segundo inciso del art. 378.2 es la prueba ya obrante en el proceso.

Otra cuestión que atender pues ha dado lugar a serias y diversas interpretaciones, es el tema de la asistencia de las partes a la audiencia (audiencia que a menudo se ha entendido que sólo debería celebrarse si hay prueba a producir). Actualmente, ante el nuevo inciso cuarto del art. 321.2 del código incorporado por la ley no 19.090 el punto parecería haber quedado resuelto: "La incomparecencia de las partes a la audiencia determinará la aplicación del art. 340” (es decir que se aplicarán las mismas reglas que para la incomparecencia a la audiencia preliminar).

Según considero ello implicará que si quién no comparece a esta audiencia de liquidación de adeudo por frutos o mejoras es el actor, se le deberá tener por desistido de su pretensión y ya no habrá más posibilidad de ejecutar luego la sentencia. A mi entender la sentencia definitiva que culmina la primera fase estableciendo el "an debeatur", lo que dispone es una condena condicional al pago de una suma; una condena condicionada a la

\footnotetext{
17 Luis Alberto Viera, "La ejecución forzada", en Curso sobre el Código General del Proceso del Instituto Uruguayo de Derecho Procesal, t. II (Montevideo, F.C.U., 1989), 153.
} 
cantidad que en la liquidación de sentencia se pueda probar o admitir que se debe, y si las partes nunca inician este procedimiento o el actor desiste de su pretensión lo que sucederá es que no se cumplirá la condición a la que estaba sometida la condena, y en definitiva no habrá condena ejecutable.

Esta conclusión de que corresponde el desistimiento de la pretensión es compartida por Klett y Vidal Lamarque, pero en cambio no conforma ni a Pereira y sus colaboradores ni tampoco a Nicastro, pues entienden que no debería quedar una sentencia de condena sin poder ser ejecutada, y entonces proponen interpretar que no es lo mismo un "incidente" (en el que según el inciso cuarto del art. 321.2 al no comparecer a la audiencia debería entenderse desistido al actor) que la "vía incidental" propuesta en el art. 378, y que entonces esta última no comprendería dicha consecuencia de la incomparecencia.

Si quien no comparece en la audiencia es el demandado, ello tendrá por consecuencia admitir los hechos alegados por el actor al evacuar el traslado de la liquidación presentada por el demandado, siempre que no contradigan la prueba ya obrante. Y esta conclusión, también compartida por Klett y Vidal Lamarque, no lo es -conforme lo expresado en el párrafo anterior- ni por Pereira y sus colaboradores ni por Nicastro.

\section{TRÁMITE PARA LIQUIDAR UNA CANTIDAD DEBIDA POR DAÑOS Y PERJUICIOS}

Cuando se trata de liquidar una cantidad debida por daños y perjuicios y según se encuentra específicamente previsto en el art. 278.3 del código, el trámite comienza con una demanda en la que el actor presentará su liquidación, formulando además en ella la proposición de los medios de prueba correspondientes.

En este caso se dará traslado por seis días (art. 99 del C.G.P.) al demandado, quién en caso de controvertir la liquidación del actor tendrá que indicar en esta evacuación del traslado los medios de prueba que quiere que se produzcan.

Conforme ha establecido la ley no 19.090 al agregar un segundo inciso al art. 378.3 para solucionar las discrepancias existentes al respecto, si el demandado no controvierte la liquidación del actor se estará a la presentada en la demanda, "salvo prueba en contrario".

Por lo demás y tomando en cuenta, en lo pertinente, lo señalado en el anterior apartado, se seguirá el trámite incidental fuera de audiencia. 


\section{SENTENCIA DE LIQUIDACIÓN}

Estando todavía vigente el C.P.C., Rafael Gallinal en 1928, Enrique Tarigo en 1974, José Arlas en 1977, Dante Barrios de Ángelis en 1982 y Jorge Marabotto en 1988, sostenían que la sentencia que establecía la cantidad de dinero adeudada por el demandado era una sentencia interlocutoria.

Así y por ejemplo, decía Barrios de Ángelis ${ }^{18}$ que

La sentencia definitiva, se dicta al término de un proceso que concluye y que es un juicio sumario u ordinario. En tanto que la sentencia interlocutoria se da al término de un proceso integrante de otro proceso, y abreviado. Es decir que, si de alguna manera tuviéramos que aplicar la solución analógica, yo diría que esta sentencia que no es definitiva y que no es interlocutoria tendría que analogarse a una sentencia interlocutoria.

Por su lado, Moretti -circa 1940- y Viera -en 1987-, sostenían que era una sentencia definitiva.

Así decía el primero ${ }^{19}$ que

Cuando se trata de sentencia dictada en juicio ordinario por reparación de daños, el mismo juicio puede decidirse definitivamente, por un solo procedimiento, con una sola sentencia, la sentencia condena al pago de una suma líquida; o por dos procedimientos, con dos sentencias: la primera condena y fija las bases, la segunda sucesiva, fija la cantidad líquida; o en tres procedimientos y en tres sentencias: la primera reserva la acción, la segunda condena y da las bases, y la tercera la suma líquida.

Cuando se aprueba y entra en vigencia el C.G.P. el asunto sigue dividiendo a Doctrina y Jurisprudencia.

Tarigo sostuvo en 1999 que la sentencia que resuelve la liquidación es una sentencia interlocutoria. A igual conclusión llegó por ejemplo la Suprema Corte de Justicia en bastante reciente sentencia no 1808/2017 (Martínez, Hounie y Minvielle, con discordia de Chediak).

Por el contrario, Teitelbaum en 1995, Klett y Álvarez Petraglia en 2006, Uriarte en 2006, Klett en 2014, Garderes en 2014 y Nicastro en 2016, han sostenido que se trata de

\footnotetext{
18 Dante Barrios de Ángelis, Graciela Barcelona, Silja Abella, "Naturaleza del proceso de liquidación de perjuicios establecidos por sentencia ejecutoriada”, en Arrendamientos Rurales y Liquidación de Perjuicios de Autores Varios (Montevideo, Alcali, 1982), 92.

19 Raúl Moretti, Estudios de Derecho Procesal, t. I (Montevideo, s/f), 103 y sigts.
} 
una sentencia definitiva (a su turno Cal sostuvo en 2015 que por su contenido la sentencia es definitiva, aunque la forma es la de interlocutoria, y a su entender ello conlleva que los requisitos para su dictado e impugnación deben ser los propios de las sentencias interlocutorias).

Y esa misma conclusión -considerar que se trata de una sentencia definitiva- sostuvo, la Suprema Corte de Justicia, por ejemplo y entre otras, en sentencia no 192/2015 (Pérez Manrique, Chediak, Larrieux, con discordias de Vázquez y Pérez Brignoni).

La definición al respecto sigue teniendo interés aún luego de vigente el C.G.P. y hasta luego de haber sido parcialmente modificado el art. 378 por la ley no 19.090 .

Se trata, en efecto, de que no habiéndose zanjado legalmente ninguna de esta cuestiones, según que se trate de una sentencia interlocutoria simple, de una sentencia interlocutoria con fuerza de definitiva o de una sentencia definitiva, va a depender la cantidad de integrantes del tribunal colegiado que deben participar de su votación (tribunal de apelaciones o Suprema Corte de Justicia), la cantidad de votos necesarios para aprobarla, los plazos de estudio y para el dictado, y hasta la posibilidad de impugnarla mediante los recursos de reposición, apelación, casación y/o revisión.

Por mi parte no tengo duda alguna de que la sentencia es una sentencia definitiva.

En la Segunda Sección del Capítulo Sexto de la Sexta Parte de "Derecho Procesal" (Montevideo, F.C.U., 2016, tomo V), a la que ahora me remito, ya expuse extensamente los claros fundamentos por los que debe entenderse que sentencia definitiva es toda aquella que resuelve el objeto (principal) del proceso (salvo que expresamente el legislador la haya calificado, asistemáticamente, de forma diversa: por ejemplo segundo inciso del art. 199.2), pudiendo además ser total o parcial; y como forma de sentencias definitivas parciales indique entonces justamente el caso de la sentencia definitiva que concluye fijando el "an debeatur" y de la sentencia, también definitiva, que complementa la anterior fijado el "quantum deleatur".

La circunstancia de que esta sentencia concluya una etapa procesal que transita por la "vía incidental" -porque el legislador se remite a ello y no por su naturaleza- y de que conforme dispuso el mismo legislador la sentencia que resuelve sobre la liquidación se apele "en la forma y en el plazo previstos para las sentencias interlocutorias", en nada cambia la conclusión sobre su naturaleza.

Y precisamente porque es una sentencia definitiva y no una sentencia interlocutoria es que, bien que cuidándose de decir que se trata de una sentencia interlocutoria, el legislador debió establecer, por una disposición especial (art. 378.4), que para apelarla se debe acudir a las mismas reglas establecidas para apelar las sentencia interlocutorias (lo que si en 
verdad esta sentencia fuera una sentencia interlocutoria, habría resultado algo totalmente innecesario, sobreabundante e inútil de establecerse por parte de ese legislador).

Por ende, la cantidad de integrantes del tribunal colegiado que deben participar de su votación, la cantidad de votos necesarios para aprobarla, los plazos de estudio y para el dictado, y las posibilidades de impugnar o no esta sentencia mediante los recursos de reposición, apelación, casación y/o revisión, serán los propios de las sentencias definitivas.

En otro orden, pero vinculado a lo anterior, respecto a la condena en costas y/o costos cabe preguntarse si esta sentencia debe seguir la regla establecida al respecto para los incidentes (art. 57 del C.G.P.).

Sobre ello entiendo, junto con Uriarte, Klett, Nicastro, etc., que la remisión a la vía incidental que formula el art. 378.1 del código no comprende el art. 57 que refiere a la condena en costas y/o costos en los incidentes, por lo cual régimen aplicable en este punto será el que con carácter general establece el art. 56.

Y agrego -coincidiendo entre otros con Klett y Álvarez Petraglia- que tampoco conduce a aplicar un sistema que implique la condena preceptiva del demandado a pagar costas y costos, el que la regulación de este procedimiento de liquidación de sentencia se encuentre inserto en la regulación que hace el código de la "Vía de Apremio", lo que conduciría (arts. 56.2 y 392 mediante) a la imposición de una condena preceptiva del demandado en costas y costos. Y no es así puesto que, como ya expuse, aunque en forma totalmente asistemática el legislador haya incluido este procedimiento en la regulación de la etapa de ejecución (y aún más concretamente en la vía de apremio), indiscutiblemente el mismo forma parte de la etapa de conocimiento del proceso y no de esa etapa de ejecución, de donde no le son aplicables las reglas que para esta última estableció ese mismo legislador.

Ahora bien y planteando otra cuestión, ¿qué debería resolver una sentencia en esta etapa de liquidación si la sentencia que declaró el "an debeatur" no estableció las "bases" para la liquidación de la condena?

Tarigo ${ }^{20}$ explicaba muy bien en que consisten estas bases:

La hipótesis es, entonces, que el Juez en su sentencia de condena, en la sentencia en que acoge la pretensión del actor, no puede, porque no tiene elementos suficientes para ello, fijar la cantidad líquida a la que ascienden los frutos o los réditos adeudados o el monto líquido de los daños y perjuicios sufridos, pero fija las 'bases' de la liquidación, esto es, expresará que condena la pago de tales frutos generados durante tal período o los réditos devengados por tal o cual concepto durante tal otro período, o condenará al pago de tales y cuales dańos y perjuicios que individualizará de la mejor manera posible aunque, claramente, sin poder determinar su cuantía.

20 Enrique Tarigo, Lecciones de Derecho Procesal Civil, tomo III, 3era. ed. (Montevideo, F.C.U., 2003), 76. 
Pues bien, en el régimen del derogado C.P.C. y según su art. 478 al dictar la sentencia claramente se podía disponer por el juez una condena "genérica", es decir sin liquidación del adeudo y sin siquiera establecer las "bases" del mismo.

Actualmente y según ya señalé, el actor puede solicitar en su demanda que se disponga la condena y que se remita la liquidación de la misma a la posterior liquidación de sentencia, mas conforme dispone el numeral 6 del art. 177 del C.G.P. esa solicitud del actor estará condicionada a que le resulte imposible indicar en su demanda la cantidad líquida (o fácilmente liquidable) que reclama, debiendo "justificar" porqué no puede establecer esa cantidad líquida. Y además, según tal disposición deberá "estimar" en dicha demanda cual sería esa cantidad e indicar cuales son las 'bases” para luego liquidarla.

Por ende, lo que no puede el actor es solicitar en su demanda una condena que no sea al pago de una cantidad líquida (o fácilmente liquidable), o una condena al pago de una cantidad ilíquida pero indicando las bases sobre las cuales debería hacerse la liquidación.

Como también antes recordé esto no es lo que, en cambio, ha apoyado Uriarte ${ }^{21}$, quién señaló que la "amplitud del texto actual nos lleva a sostener que la sentencia de condena ilíquida puede o no contener las bases de la liquidación. Por otra parte, la lectura del artículo 11 del C.G.P. nos reafirma en esta convicción”.

Y en cuanto a la posibilidad de que una sentencia remita al procedimiento del art. 378 del código para liquidar la cantidad adeudada, pero sin fijar las bases, también ha expresado luego Klett ${ }^{22}$ : “(...) que la ley procesal no prevé la necesidad (deber judicial) de consignar las pautas según las cuales se llevará adelante el procedimiento (art. 378), como lo hacía el CPC. La experiencia enseña que, en muchos casos, no se establecen las bases, lo que ratifica la vigencia de la denominada 'condena genérica' a que refiere Tarigo."

Por mi parte y según he adelantado, coincido en cambio con lo que ya en 1995 (y también luego en 1999 y en su póstumo libro de 2003) sostenía Tarigo ${ }^{23}$, respecto a que la redacción del C.G.P. -incluido lo que dispone el numeral 6 del art. 117- "supone la negación de la tercera posibilidad prevista por el art. 478 C.P.C., esto es, la posibilidad de la condena genérica”.

De manera que según entiendo el actor puede pedir la condena del demandado al pago de una suma ilíquida, pero en tal caso deberá de todas formas estimar cuál es la cantidad

${ }_{21}$ Uriarte, "Algunas reflexiones, 6; Gonzalo Uriarte, "Vía de apremio. Algunos títulos y preparación de la misma”, en Estudios sobre el proceso de ejecución en homenaje a Enrique E. Tarigo de Autores Varios (Montevideo, F.C.U., 2006), 110 .

Klett, Proceso Ordinario, 239.

23 Tarigo, "Frente a la sentencia, 228; y Lecciones, 83. 
adeudada y justificar porqué no ha podido liquidarla y, además, indicar las "bases” en las que se funda para tal estimación (las que luego deberán seguirse para la liquidación posterior).

Por ende, si no se solicita en la demanda ni la condena del demandado a pagar una suma líquida, ni su condena a pagar una suma ilíquida, pero indicando las bases que luego servirán para liquidarla, considero que ya al controlar la demanda el juez debería disponer que se subsane el defecto "en el plazo que se seńale con apercibimiento de tenerla por no presentada” (art. 119.1 del código). Y si el juez no se apercibe del defecto de esta, entonces corresponderá al demandado impugnar la resolución inicial del juez que tuvo por bien presentada la demanda, empleando al efecto la excepción previa de defecto en el modo de proponer la demanda (numeral 3 del art. 133.1 C.G.P.). Y si ni el juez inicialmente ni luego el demandado advierten el defecto en cuestión, corresponderá después a dicho juez rechazar la demanda al momento de dictar la sentencia definitiva.

Todo lo anterior no implica rechazar la posibilidad, remota pero admisible, de que resulte admisible comprender en esta etapa de liquidación de sentencia algunos rubros que no estaban comprendidos en las "bases" pero que corresponden a "hechos nuevos" en el sentido de esta terminología empleado por el propio C.G.P.; es decir rubros cuya existencia recién se conoce por el actor al momento de presentarse la demanda de liquidación de sentencia o en el curso de su tramitación.

Veamos ahora una última cuestión, referida está acerca de lo que debe resolver el juez cuando las resultancias de los medios de prueba obrantes (en la propia liquidación de sentencia, pero quizás también en la anterior faz de conocimiento), no permiten concluir con certeza sobre la cantidad a la que debe ascender la condena que concluye este trámite de liquidación.

Coincidiendo en lo esencial al respecto con Uriarte y con Klett (bien que quizás no con todos sus argumentos) y discrepando en esto con Tarigo, entiendo que no siempre la sentencia que pone fin al procedimiento de liquidación debe indicar que el demandado tiene que abonar al actor una cantidad determinada.

Lo que si entiendo y ya adelanté, es que en estos casos lo que debe hacer el juez que interviene en el procedimiento de liquidación de sentencia (en el que naturalmente tendrá que tener en cuenta las bases que tuvo que haber establecido la sentencia definitiva cuya condena se está liquidando), no es rechazar directamente la pretensión de liquidación cuando con la prueba hasta entonces obrante no puede llegar a la convicción acerca de la cantidad adeudada, sino previamente acudir a todos los mecanismos que señalé precedentemente; es decir al procedimiento previsto en el art. 1611 del Código Civil (juramento estimatorio), y, 
en ciertos casos, a disponer de oficio la producción de otros medios de prueba (en particular a través de las llamadas "diligencias para mejor proveer": art. 193 del C.G.P.), o acudir a las liquidaciones "imperfecta” o "equitativa" que menciona entre nosotros especialmente Gamarra y a las cuales ya me he referido precedentemente.

Claro está que si aún así no se logra comprobar la existencia de alguna cantidad comprendida en la condena establecida en la sentencia que se está liquidando, la sentencia que culmina este procedimiento del art. 378 del código así deberá declararlo, pues la sentencia definitiva cuya condena se pretende liquidar es en realidad una sentencia condicional: condena al pago de aquellas sumas que se demuestre que se adeudan conforme a las bases establecidas $y$, por ende, si luego de agotarse todos los medios propuestos por las partes y el empleo por el juez de los mecanismos señalados, no se demuestra que se adeude alguna cantidad, la sentencia debería limitarse a indicar que no se condena al pago de suma alguna.

\section{RECURSOS}

En el art. 378.4 del código se establece una previsión respecto a la impugnación de las resoluciones dictadas en el procedimiento de liquidación de sentencia.

En su actual redacción dicha disposición indica que solamente puede apelarse "la sentencia que resuelva sobre la liquidación", agregando que ello debe hacerse "en la forma y en el plazo previstos para las sentencias interlocutorias, con efecto suspensivo".

Ya al aprobarse en el C.G.P. el texto originario de este art. 378.4 se solucionaron las discusiones existentes en Doctrina y Jurisprudencia durante la vigencia del C.P.C. respecto a si podía y a como podía apelarse esta sentencia, y ahora con el texto dado por la ley no 19.090 se solucionaron las discusiones que seguían existiendo respecto a dicha apelación (cuya interposición ahora tendrá indiscutiblemente efecto suspensivo).

De manera que sin que ello signifique que la sentencia que resuelve sobre la liquidación sea una sentencia interlocutoria, conforme lo dispuso el legislador la apelación deberá realizarse como si fuera tal.

En consecuencia, si la sentencia se dicta en el curso de una audiencia, según el art. 254.2 el apelante tendrá que anunciar el recurso en la misma e interponer los fundamentos por escrito dentro del plazo de seis días. Si la sentencia se dicta fuera de audiencia conforme al art. 
254.2 el apelante tendrá que interponer el recurso con sus fundamentos dentro de los seis días siguientes.

En todo caso la interposición de la apelación tendrá efecto suspensivo de su ejecución, y si bien nada se indica explícitamente respecto a si el trámite de la apelación debe ser o no diferido, dado que no existirá ninguna sentencia posterior que pueda ser apelada necesariamente será un trámite no diferido.

Las cuestiones que, en cambio y sobre recursos, quedan sin resolver son otras que analizaré a continuación.

a) Si la sentencia que pone fin al procedimiento de liquidación de sentencia no resuelve sobre la liquidación en si misma, sino que por ejemplo tiene por desistido al actor por no comparecer a la audiencia, ¿ella es apelable?

Respecto a la posibilidad de apelar una sentencia que tiene al actor por desistido por no comparecer en la audiencia, Garderes ${ }^{24}$ ha sostenido que

No parece razonable que, si admite apelación toda sentencia interlocutoria que ponga fin al proceso de ejecución (art. 393.2, inciso $1^{\circ}$ ) no admita apelación toda sentencia que ponga fin al proceso de liquidación del art. 378, siendo que las razones que justifican la limitación de la apelación en el proceso de ejecución no se dan en el proceso de liquidación. En definitiva, considero que admite apelación toda sentencia que ponga fin al proceso de liquidación del art. 378, ya sea que se pronuncie sobre la pretensión de liquidación o que de otra forma le ponga fin al proceso, y en ese sentido amplio (quizás debió decir "restringido") debe interpretarse la referencia legal del art. 378.4 a 'la sentencia que resuelva sobre la liquidación'.

A su turno Nicastro ha indicado que comparte la argumentación y la conclusión de Garderes.

Personalmente, y aunque entiendo muy bien el fundamento comparativo empleado por Garderes, considero que la expresión del art. 378.4 del código ("Únicamente será apelable") no admite ser interpretada de manera diferente a la que resulta de su sentido literal. Se trata, en efecto, de que si el legislador dice claramente que "únicamente" es apelable la sentencia que resuelva sobre la liquidación, esta diciendo, indiscutiblemente, que cualquier otra sentencia que se dicte -que siempre va a ser una sentencia que no resuelve sobre la liquidación- es inapelable. Cosa diferente de la inapelabilidad consagrada es la de si la misma sienta una buena solución, y en este sentido parece claro, por lo que argumenta Garderes,

\footnotetext{
24 Santiago Garderes, "Modificaciones a la vía de apremio (ley no 19.090)", en Curso sobre la reforma del Código General del Proceso (Ley 19.090), obra colectiva (Montevideo, La Ley Uruguay, 2014), 202.
} 
que la consagrada no es una buena solución y que la disposición no es coherente con otras regulaciones del mismo código. Pero no corresponde al intérprete corregir al legislador.

b) ¿Es admisible interponer contra resoluciones dictadas en el curso de esta liquidación de sentencia los recursos de aclaración y/o ampliación?

No existiendo limitación legal al respecto debe aplicarse lo que sobre la aclaración y ampliación dispone el art. 244.4 del código: "Estos recursos proceden respecto de toda clase de resoluciones. Podrán ser usados una sola vez por cada una de las partes y en relación con cada resolución”.

c) ¿Es admisible interponer contra resoluciones dictadas en el curso de esta liquidación de sentencia el recurso de reposición?

En cuanto al recurso de reposición existe total coincidencia de que el mismo corresponde contra toda resolución adoptada en el curso de la liquidación de sentencia (art. 245 y también art. 322.1 del código por la remisión a la "vía incidental" que efectúa el art. 378.1). E inclusive, conforme lo indicaba expresamente el texto del art. 378.4 del código en su redacción original, este recurso también procedía contra la sentencia que ponía fin al procedimiento. Habiéndose ahora modificado dicho texto por la ley no 19.090 , se eliminó del mismo la referencia a la admisibilidad del recurso de reposición contra la sentencia que resuelve sobre la liquidación, por lo que para adoptar posición sobre esta cuestión deberá atenderse a la naturaleza de esa sentencia. De allí que para todos quienes hemos sostenido que se trata de una sentencia definitiva, no será admisible que contra ella se interponga un recurso de reposición (y, en cambio, si lo será para quienes han entendido que se trata de una sentencia interlocutoria).

d) ¿Es admisible interponer contra resoluciones dictadas en el curso de esta liquidación de sentencia el recurso de casación?

Asimismo, para todos aquellos que hemos concluido que la resolución que se pronuncia sobre la liquidación es una sentencia definitiva (y aún para quienes entienden que es una sentencia interlocutoria, pero con fuerza de definitiva), cuando la misma es dictada en segunda instancia admitirá ser impugnada a través del recurso de casación (art. 268 del C.G.P.).

Así se pronuncian explícitamente al respecto, afirmando la posibilidad de impugnación de esa sentencia a través del recurso de casación, Teitelbaum, Klett y Álvarez Petraglia, Uriarte, nuevamente Klett y Nicastro, e incluso hasta Cal pese a sostener que la sentencia en cuestión debe ser tratada en cuanto a su forma como una interlocutoria (aparentemente simple). 
e) ¿Es admisible interponer contra resoluciones dictadas en el curso de esta liquidación de sentencia el recurso de revisión?

Teniendo presente que el recurso de revisión puede interponerse contra las sentencias interlocutorias con fuerza de definitiva y contra las sentencias definitivas firmes (art. 281 del C.G.P.), debemos concluir que será admisible la revisión para impugnar las sentencias interlocutorias con fuerza de definitiva que pudieren dictarse en el curso del procedimiento, y también contra la sentencia que pone fin al mismo (salvo que, lo que naturalmente no comparto, que pudiere entenderse que la misma es una sentencia interlocutoria simple).

\section{CONCLUSIONES}

10 Eventualmente pueden presentarse en un proceso dos etapas de formación progresiva de una única sentencia de condena, que es la que en definitiva se va luego a ejecutar (una única sentencia de condena comprensiva ella de dos sentencias parciales que se complementan, en tanto una determina el "an debeatur", y la otra, si la primera fue de condena, el “quantum debeatur").

$2^{\circ}$ El C.G.P. prevé en su art. 378 un procedimiento que aunque insertado asistematicamente en la "Vía de apremio", no forma parte de la etapa de ejecución sino de la etapa de conocimiento del proceso.

3o La sentencia que pone fin al trámite de la liquidación de sentencia -pese a tratarse de un procedimiento que sin ser un incidente sigue por disposición legal el tracto de los incidentes tramitados fuera de audiencia- es una sentencia definitiva.

40 Existe iliquidez de la sentencia de condena, habilitando así el inicio de este procedimiento, cuando la misma no está cuantitativamente determinada en términos de una unidad de medida, aunque no debe considerarse ilíquida a aquella condena cuyo monto es "fácilmente liquidable".

El actor puede pedir la condena del demandado al pago de una suma ilíquida, pero en ese caso deberá estimar cuál es la cantidad adeudada y justificar porqué no ha podido liquidarla y, además, indicar las “bases” para la liquidación posterior.

Ninguna disposición del actual código, es decir del C.G.P. indica -ni siquiera indirectamente- que el juez está autorizado a no seguir la regla general o principio de la necesaria congruencia de las sentencias, y a dejar de pronunciarse -acogiéndola o no- respecto a la parte de 
la pretensión del actor referida a la suma (liquida o fácilmente liquidable) a cuyo pago ese actor ha solicitado que se condene al demandado. Si es necesario para poder pronunciarse el juez deberá acudir en los casos que sea admisible al juramento estimatorio, a los medios de prueba que se le admite producir de oficio (en especial a través de las "diligencias para mejor proveer"), y eventualmente a las liquidaciones "imperfectas" o "equitativas".

Con mucho esfuerzo podría intentarse encontrar una norma habilitante para emplear este procedimiento en otros supuestos diferentes de los configurados cuando la deuda es por frutos, mejoras, daños o perjuicios, y para ello se podría hacer base en el numeral 6 del art. 117 y en el art. 378.1 del C.G.P. puesto que los mismos parecieran establecer una posibilidad genérica de acudir a este procedimiento y no sólo limitada a los citados supuestos.

Es admisible acudir a este procedimiento, aunque el adeudo ilíquido no resulte de una sentencia sino de otros actos jurídicos asimilados a las sentencias, pero diferentes de estas.

$5^{\circ}$ Los tribunales que entendieron en la primera instancia y en la segunda instancia de la etapa de conocimiento son los competentes para el procedimiento de liquidación de sentencia.

6o Este procedimiento solamente puede iniciarse a solicitud de parte y nunca de oficio, bien que actualmente la demanda puede ser presentada por cualquiera de las dos partes.

70 Lo único que se puede diferir a la liquidación de sentencia es la cuantificación de la suma a cuyo pago se condenó al demandado, sin perjuicio de que debe admitirse la cuantificación de daños que ingresen por la vía de hechos nuevos.

$8^{\circ}$ Cuando se trata de liquidar una cantidad debida por frutos o mejoras según el art. 378.2 del código el trámite comienza con una demanda de liquidación en la que se solicita intimar al condenado para que él presente esa liquidación. Otorgado el traslado al demandado y presentada la liquidación por el mismo deberá darse traslado al actor, quién podrá formular una liquidación alternativa. Luego se seguirá el trámite de los incidentes fuera de audiencia.

Si el demandado no presenta una liquidación habrá de estarse a la que presente el actor "salvo prueba en contrario". Si al contestar la demanda el demandado presenta la liquidación y en el término del traslado que corresponde ella no es controvertida por el actor, deberá estarse a la liquidación que presentó el demandado.

Si el demandado no presenta una liquidación se suspenderá el trámite hasta que el actor presente la suya.

Si las partes no comparecen a la audiencia se les aplicará lo que resulta del art. 340 para la Audiencia Preliminar. 
90 Para liquidar una cantidad debida por daños y perjuicios, según el art. 378.3 el actor presentará su liquidación, dándose traslado por seis días. Si el demandado no controvierte se estará a la liquidación presentada en la demanda, "salvo prueba en contrario". Por lo demás se seguirá el trámite incidental fuera de audiencia.

10' La sentencia final del trámite de liquidación de sentencia es una sentencia definitiva. La cantidad de integrantes del tribunal colegiado que deben participar de su votación en segunda instancia, la cantidad de votos necesarios para aprobarla, los plazos de estudio y para el dictado, y las posibilidades de impugnar o no esta sentencia mediante los recursos de reposición, apelación, casación y/o revisión, serán los propios de las sentencias definitivas.

La remisión a la vía incidental que formula el art. 378.1 del código no comprende el art. 57 que refiere a la condena en costas y/o costos en los incidentes, por lo cual régimen aplicable en este punto será el que con carácter general establece el art. 56.

Si no se solicita en la demanda ni la condena del demandado a pagar una suma líquida, ni su condena a pagar una suma ilíquida, pero indicando las bases que luego servirán para liquidarla, ya al controlar la demanda el juez debería disponer que se subsane el defecto "en el plazo que se señale con apercibimiento de tenerla por no presentada" (art. 119.1 del código). Y si el juez no se apercibe del defecto de esta, entonces corresponderá al demandado impugnar la resolución inicial del juez que tuvo por bien presentada la demanda, empleando para ello la excepción previa de defecto en el modo de proponer la demanda (numeral 3 del art. 133.1 C.G.P.). Y si ni el juez inicialmente ni luego el demandado advierten el defecto en cuestión, corresponderá después a dicho juez rechazar la demanda al momento de dictar la sentencia definitiva.

Si aún luego de emplear todos los mecanismos correspondientes el juez no logra comprobar la existencia de alguna cantidad comprendida en la condena establecida en la sentencia que se está liquidando, así deberá declararlo al dictar la sentencia que culmina este procedimiento del art. 378.

11- Solamente puede apelarse "la sentencia que resuelva sobre la liquidación", y ello debe hacerse "en la forma y en el plazo previstos para las sentencias interlocutorias, con efecto suspensivo".

No existiendo limitación legal al respecto debe aplicarse lo que sobre los recursos de aclaración y ampliación dispone el art. 244.4 del código.

El recurso de reposición es admisible contra toda resolución adoptada en el curso de la liquidación de sentencia, aunque no contra la sentencia final pues la misma es una sentencia definitiva. 
Cuando la sentencia final es dictada en segunda instancia admitirá ser impugnada a través del recurso de casación.

Es admisible el recurso de revisión para impugnar las sentencias interlocutorias con fuerza de definitiva que pudieren dictarse en el curso del procedimiento, y también contra la sentencia que pone fin al mismo.

Para citar este artículo: Abal Oliú, Alejandro, "Liquidación de sentencia", Revista de Derecho. Ucudal No 18 (Dic.- 2018), ISSN 1510-3714, ISSN On line 2393-6193, $11-44$.

\section{BIBLIOGRAFÍA}

Arlas, José, "Ejecución de sentencia con condena genérica al resarcimiento de daños y perjuicios”, Rev. de Derecho Público y Privado, t. XXV, Montevideo, 1950, 231/239.

Arlas, José, "Ejecución de sentencias", en Curso de Derecho Procesal del Instituto Uruguayo de Derecho Procesal, t. IV, Facultad de Derecho y Ciencias Sociales, Montevideo, 1977, 63/72.

Barrios de Ángelis, Dante, Barcelona, Graciela, Abella, Silka, "Naturaleza del proceso de liquidación de perjuicios establecidos por sentencia ejecutoriada”, en Arrendamientos Rurales y Liquidación de Perjuicios de Autores Varios, Alcali, Montevideo, 1982, 75/116.

Barrios de Ángelis, Dante, El proceso civil, vol. Segundo, Idea, Montevideo, 1990, 147/149. Cal Laggiard, Maximiliano, "Sobre la naturaleza jurídica del incidente de liquidación de sentencia”, Rev. Uruguaya de Der. Procesal, Montevideo, 1/2015, 155/170.

Couture, Eduardo J., "Doctrina y Jurisprudencia anteriores en materia de liquidación de sentencia con condena genérica en daños y perjuicios", Rev. de Derecho, Jurisprudencia y Administración, t. XXXV, Montevideo, 1937, 90/91.

Couture, Eduardo J., Fundamentos del Derecho Procesal Civil, tercera edición, Depalma, Buenos Aires, 1966, 457/458.

Cutrín Piñeiro, José M., "Anotaciones sobre el proceso de ejecución de sentencia", III Jornadas Nacionales de Técnica Forense, F.C.U., Montevideo, 1993, 35/36.

De María, Pablo, Lecciones de Procedimiento Civil, t. II, Claudio García, Montevideo, 1927, $225 / 226$ y $243 / 247$. 
Delle Piane, A. L., "Origen y fundamento de las disposiciones legales en materia de ejecución de sentencias que condenan al pago de cantidad ilíquida”, Rev. de Derecho, Jurisprudencia y Administración, t. XXXVI, Montevideo, 1938, 204/207.

Gallinal, Rafael, Estudios sobre el Código de Procedimiento Civil (Ejecución de sentencias. Ejecución de sentencia extranjeras. Terceros opositores en juicio ordinario. Desistimiento y deserción), Casa A. Barreiro y Ramos S.A., Montevideo, 1928, 122/159.

Gallinal, Rafael, Manual de Derecho Procesal Civil, t. II, Barreiro y Ramos, Montevideo, 1930, 118.

Gamarra, Jorge, Tratado de Derecho Civil Uruguayo, t. XXIV, F.C.U., Montevideo, 1992, $88 / 108$ y $255 / 295$.

Garderes, Santiago, "Modificaciones a la vía de apremio (ley no 19.090)" en Curso sobre la reforma del Código General del Proceso (Ley 19.090), obra colectiva, La Ley Uruguay, Montevideo, 2014, 199/203.

Klett, Selva, Álvarez Petraglia, Federico, "El recurso de apelación en la vía de apremio" (Sobre apelación de sentencia que decide el incidente de liquidación), en Estudios sobre el proceso de ejecución en homenaje a Enrique E. Tarigo de autores varios, F.C.U., Montevideo, 2006, 55/56.

Klett, Selva, Proceso Ordinario, t. III, F.C.U., Montevideo, 2014, 232/253.

Marabotto, Jorge, “Dos temas de interés: a) ¡es definitiva o interlocutoria la sentencia que liquida los daños; b) ¿̨nunca el error, vicia los actos procesales?, Rev. Judicatura, no 23, Montevideo, 1988, 40/43.

Nicastro, Gustavo, "Cuestiones prácticas en el proceso de liquidación de sentencia previsto en el artículo 378 del C.G.P.”, Rev. Judicatura, no 60, Montevideo, 2016, 133/143.

Pereira Campos, Santiago y Otros, Código General del Proceso. Reformas de la ley 19.090, Universidad de Montevideo, 2013, 428/430.

Tarigo, Enrique, "Ejecución de sentencia que condena al pago de sumas ilíquidas", Rev. Uruguaya de Der. Procesal, Montevideo, 4/1993, 575/578.

Tarigo, Enrique, "El proceso de ejecución de sentencia, si ésta condena al pago de suma ilíquida, debe ser precedido del de liquidación”, Rev. Uruguaya de Der. Procesal, Montevideo, 1/2002, 127/131.

Tarigo, Enrique, "Frente a la sentencia definitiva que condenó a indemnizar daños y perjuicios y fijó las bases de tal liquidación, la sentencia interlocutoria de liquidación de sentencia no puede dejar de fijarlos”, Rev. Uruguaya de Der. Procesal, Montevideo, 2/1995, 225/232. 
Tarigo, Enrique, "Liquidación de sentencia con condenación en costos" (¿Se puede determinar por esta vía el monto de las costas y costos?), Rev. Uruguaya de Der. Procesal, Montevideo, 1/2002, 115/119.

Tarigo, Enrique, "Sentencia definitiva ejecutoriada de condena y sentencia interlocutoria de liquidación”, Rev. Uruguaya de Der. Procesal, Montevideo, 4/2000, 531/534.

Tarigo, Enrique, Lecciones de Derecho Procesal Civil, tomo III, 3era. ed., F.C.U., Montevideo, 2003, 76/83.

Teitelbaum, Jaime, "Proceso de ejecución y vía de apremio", Rev. Uruguaya de Der. Procesal, Montevideo, 4/1995, 515/516.

Uriarte Audi, Gonzalo, "Vía de apremio. Algunos títulos y preparación de la misma”, Estudios sobre el proceso de ejecución en homenaje a Enrique E. Tarigo de Autores Varios, F.C.U., Montevideo, 2006, 109/114.

Uriarte, Gonzalo, "Algunas reflexiones sobre el proceso de liquidación de sentencia”, Tribuna del Abogado, no 134, Montevideo, 2003, 5/7.

Uruguayo de Derecho Procesal, t. IV, 2da. ed., F.C.U., Montevideo, 1987, 60/66.

Valentin, Gabriel, La Reforma del Código General del Proceso, F.C.U., Montevideo, 2014, $368 / 372$.

Veiras, Jorge, "Código General del Proceso. Modificaciones introducidas por la ley no 19.090", Rev. Uruguaya de Der. Procesal, Montevideo, 2/2012, 969/970.

Vidal Lamarque, Alvaro, "Estudio sobre la incomparecencia del demandado a la audiencia preliminar del proceso ordinario, así como a la audiencia única en otras clases de procesos regulados en C.G.P. Efectos y consecuencias”, Rev. Doctrina \& Jurisprudencia (CADE), tomo XLV, 2018, 95.

Viera, Luis A., "Ejecución de sentencia”, en Curso de Derecho Procesal del Instituto Viera, Luis Alberto, "La ejecución forzada”, en Curso sobre el Código General del Proceso del Instituto Uruguayo de Derecho Procesal, t. II, F.C.U., Montevideo, 1989, 153. 